\title{
Effect of Glabridin on Microvascular Permeability of Plasma Proteins Induced by Carrageenan
}

\author{
Rabia Edibe Parlar Köprülï ${ }^{1(\mathbb{D})}$, Ali Parlar ${ }^{2, *}{ }^{\mathbb{D}}$, Saliha Ayşenur Çam ${ }^{3(\mathbb{D})}$, Seyfullah Oktay Arslan ${ }^{3(\mathbb{D})}$ \\ Faculty of Pharmacy, Medipol University, Istanbul, Turkey \\ Department of Pharmacology, Faculty of Medicine, University of Adiyaman, Adiyaman, Turkey \\ Department of Pharmacology, Faculty of Medicine, University of Yildirim Beyazit, Ankara, Turkey \\ * Correspondence: parlar.ali@hotmail.com;
}

Scopus Author ID 57200165688

Received: 23.04.2021; Revised: 28.05.2021; Accepted: 30.05.2021; Published: 18.06.2021

\begin{abstract}
In the present study, investigate the anti-inflammatory effects of glabridin (GLA) in the carrageenan-induced paw edema test of rats. Inflammation is an answer to the body's immune response to various stimuli such as physical trauma, various antigens, chemicals, microorganisms, radiationdamaged tissues. The cause of this edema is the increase of vascular permeability, an increase in local blood flow, as well as the penetration of neutrophils and macrophages into the inflamed tissue. The current study aimed to determine the mechanism of microvascular leakage on carrageenan (CAR)induced paw edema of GLA. Therefore, 10, 20 and $40 \mathrm{mg} / \mathrm{kg}$ doses of GLA were given intraperitoneal 3 days before intraplantar administration of CAR by using Evans blue (EB) method and by measuring paw thickness with electronic digital calipers. As a result, GLA inhibited both edema and microvascular leak. The results of our study suggest that pretreat-GLA to CAR-induced paw edema of rats via antiinflammatory potential through inhibition of parameters such as microvascular escape and antiedematous effect. These findings may be a new treatment of inflammation by anti-protein leakage of GLA.
\end{abstract}

Keywords: glabridin; inflammation; Evans blue dye; carrageenan; Glycyrrhiza glabra.

(C) 2021 by the authors. This article is an open-access article distributed under the terms and conditions of the Creative Commons Attribution (CC BY) license (https://creativecommons.org/licenses/by/4.0/).

\section{Introduction}

Inflammation is an answer to the body's immune response to various stimuli such as physical trauma, various antigens, chemicals, microorganisms, radiation-damaged tissues. These responses are pain, heat, redness, edema and loss of function. The cause of this edema is the increase of vascular permeability, an increase in local blood flow, as well as the penetration of neutrophils and macrophages into the inflamed tissue [1]. Previous studies have shown that inflammation is associated with many diseases such as tissue injury, diabetes, asthma, inflammatory bowel disease, carcinoma, and atherosclerosis [2,3]. There are two phases in acute inflammation. In the first phase, mediators such as 5-hydroxytryptamine, histamine and bradykinin are released within 60 minutes [4]. In the second phase, the edema in which the prostaglandins are released remains 5 hours [5]. In the acute inflammatory process, as a result of the increased permeability of vascular via cytokines or mediators, local edema occurs as a result of leakage of fluid and plasma proteins into the area leading to the formation of both leukocyte-dependent and non-leukocyte-dependent [6].

Although there are many experimental inflammation models for research, carrageenan (CAR)-induced paw edema, resulting in vascular changes, oxidative stress with the increase 
lipid peroxidation or the depletion of antioxidant sulfhydryl pool such as glutathione, is the standard experimental model of acute inflammation, originally described by Kumari et al. (2020) [7].

For many centuries, licorice root (Glycyrrhiza glabra) has been used for medical purposes such as ulcers, bronchitis and bacterial infections in some countries such as India, China. Since the discovery of glabridin (GLA), an isoflavone isolated from licorice root, in 1976, cosmetic preparations have been prepared and used in antioxidant and anti-inflammatory diseases [8]. Glycyrrhiza glabra, well-known for its antioxidant and anti-inflammatory properties, has been the focus of interest for researchers in this field [9-12].

Glabridin, one of the main components that make up the Glycyrrhiza glabra, has been proven to have anti-nociceptive and anti-inflammatory effects with our previous study [13]. In another study, glabridin given to rats 5 days earlier was shown to ameliorate carrageenaninduced paw edema [14]. Therefore, the current study was designed to investigate the antiinflammatory effects of GLA in the CAR-induced paw edema test of rats.

\section{Materials and Methods}

\subsection{Chemicals.}

CAR, Evans Blue and GLA were purchased from Sigma-Aldrich (USA), Fluka and Xi' an ZB Biotech Co., Ltd. (Shaanxi, Chine), respectively. Dimethyl sulfoxide (DMSO) was used as the solvent.

\subsection{Experimental animals.}

Male albino-Wistar rats with an average weight of 250+_10 g were used in the study. The animals used were obtained from Adiyaman University Experimental Research Center. Ethical permission certificate was obtained from Adiyaman University Animal Experiments Local Ethics Committee (2019/009) where the study was conducted. Rats were randomly housed in appropriate cages at $22 \pm 2{ }^{\circ} \mathrm{C}$ under a $12 / 12$-h dark/light cycle with free access to tap water and commercial rat chow. Procedures were in accordance with the Guide for Care and Use of Laboratory Animals.

\subsection{Experimental design.}

After the rats were randomly divided into 6 groups of 6-8 rats in each cage, they were taken to the laboratory where the experiments will be performed and four days were kept for acclimatization. Groups were named saline control, DMSO, CAR, GLA-10, GLA-20 and GLA40, respectively. Carrageenan was administered intraplantar to groups but saline control group. Three days before carrageenan administration, GLA-10, GLA-20 and GLA-40 groups were treated with GLA at a dose of 10,20 and $40 \mathrm{mg} / \mathrm{kg}$, respectively, for 3 days.

\subsection{Carrageenan-induced paw edema.}

Inflammation was induced by intraplantar injection of carrageenan $(100 \mu 1,1 \%)$ into the paws of rats. The increase in paw thickness $(\mathrm{mm})$ measured before and after CAR injection for each animal was expressed as EDEMA. Paw thicknesses were measured with an electronic digital caliper before and 1/4 hour after CAR application, which corresponds to the maximum edema time. Plasma extravasations were measured by injecting Evans blue dye into the tail vein 
15 minutes before the end of the experiment [15]. Animals treated with formaldehyde were killed by guillotine decapitation and hind paws incubated with formamide for 48 hours. The dye was then extracted and measured by spectrophotometry at $620 \mathrm{~nm}$. This procedure has been used in previous studies.[1,16].

\subsection{Statistical analysis.}

All statistical analyzes of the study were performed using GraphPad from the software. All data were presented and accepted as mean \pm standard deviation mean. Differences between groups were compared using Student's t test or one-way ANOVA followed by Tukey's Multiple Comparison and a $\mathrm{P}<0.05$ was considered significant.

\section{Results and Discussion}

\subsection{Evaluation of the carrageenan-induced paw edema.}

The anti-inflammatory activities of GLA on carrageenan-induced acute paw edema were shown in Figure 1. Administer of carrageenan caused edema in paw tissue $(* \mathrm{P}<0.001)$. Pretreatment of rats with 20 or $40 \mathrm{mg} / \mathrm{kg}$ dose of GLA (**P<0.05 or *** $<<0.01)$ significantly attenuated carrageenan-induced paw edema, but administer of $10 \mathrm{mg} / \mathrm{kg}$ dose GLA was not statistically significant when compared to CAR-treated group ( $\mathrm{P}>0.05)$ (Figure 1).

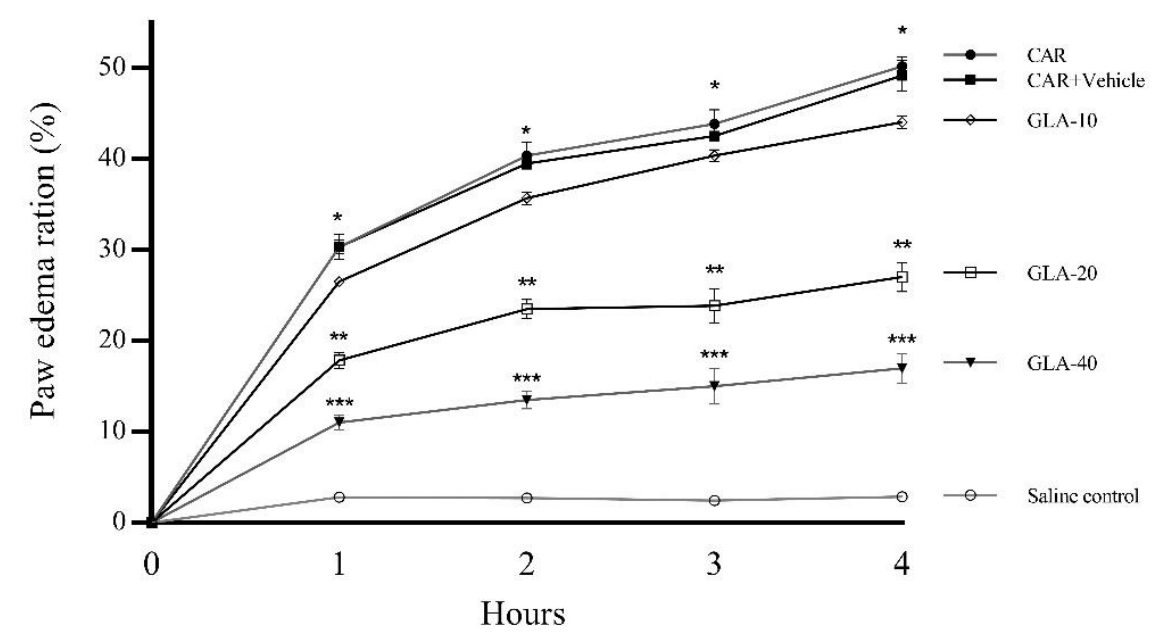

Figure 1. Effects of GLA on the carrageenan-induced paw edema formation. Rats were evaluated for paw edema at $0,1,2,3$ and $4 \mathrm{~h}$ post-carrageenan injection. Results were expressed as the percentage increase in paw thickness. Each point represents the mean \pm SEM $(n=6)$ and one-way ANOVA followed by Tukey's multiple range test. CAR treated led to edema $\left({ }^{*} \mathrm{P}<0.001\right)$ as compared to Salin control group, pretreatment of $20 \mathrm{mg} / \mathrm{kg}$ dose of GLA found statistically significant $\left({ }^{* *} \mathrm{P}<0.05\right)$ as compared to CAR group and $40 \mathrm{mg} / \mathrm{kg}$ dose of GLA

$\left({ }^{* * *} \mathrm{P}<0.01\right)$ inhibited CAR-induced paw edema as compared to CAR group.

\subsection{The effect of GLA on plasma extravasation in carrageenan-induced paw edema.}

Figure 2 illustrated that the inhibitory effect of GLA on plasma extravasation in carrageenan-induced paw edema was clearly inhibited. Moreover, administer 20 or $40 \mathrm{mg} / \mathrm{kg}$ dose of GLA $(* \mathrm{P}<0.05$ or $* * \mathrm{P}<0.01)$ significantly attenuated carrageenan-induced paw edema, whereas this effect was not found statistically significant in administering of GLA $10 \mathrm{mg} / \mathrm{kg}$ dose. 


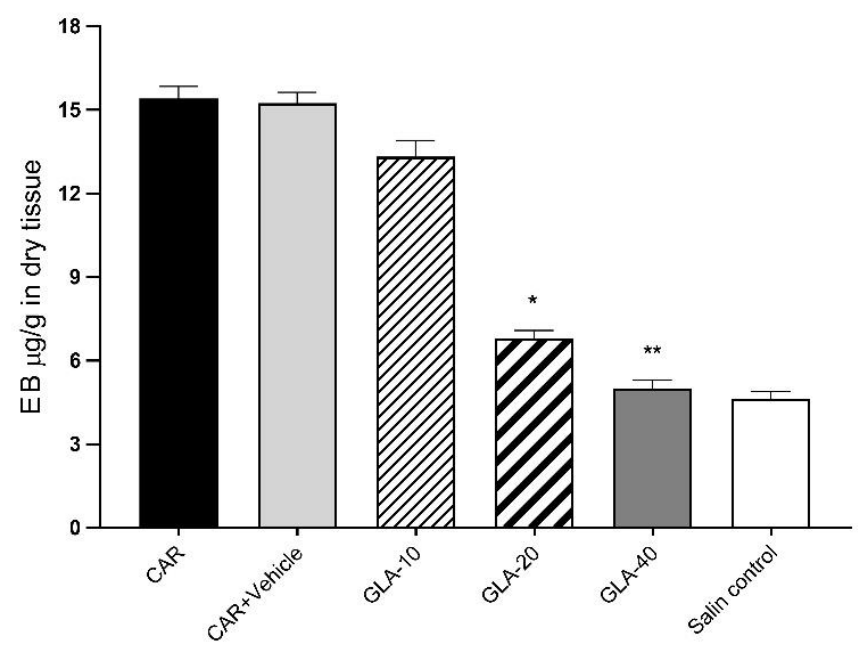

Figure 2. The CAR-induced inflammation in paw tissue and the effect of GLA on plasma extravasation. Data are expressed as mean \pm S.E.M. $(n=6)$ and one-way ANOVA followed by Tukey's multiple range test. $20 \mathrm{mg} / \mathrm{kg}$ dose of GLA inhibited plasma extravasation ( $\left.{ }^{*} \mathrm{P}<0.05\right), 40 \mathrm{mg} / \mathrm{kg}$ dose of GLA significantly led to inhibition of edema $\left({ }^{* *} \mathrm{P}<0.01\right)$ as compared to CAR group, but lover dose of GLA statistically no significant.

\subsection{Discussion.}

It is well-known CAR-induced paw edema is the standard model of acute inflammatory studies. Following CAR-injection, acute inflammation occurs within the first few hours, which consists of two phases. While the kinins, serotonin and histamine are released in the first phase, the prostaglandins are released within 2-3 hours in the second phase [17,18], in which vasodilatation, protein leakage and edema occur by the release of vasoactive peptides such as neurokinin A, substance $P$ and calcitonin gene-related peptide through the acute period $[19,20]$.

In the current study, CAR was administered to the rat paw to determine if the GLA improved edema. GLA significantly led to reducing the plasma extravasations in CAR-induced inflammation of rat paw. In the previous study, paw thickness was found statistically significant in the treatment CAR group at $1 \mathrm{~h}, 2 \mathrm{~h}, 3 \mathrm{~h}$ and $4 \mathrm{~h},(6,25 \pm 0,147,6,46 \pm 0,216,6,64 \pm 0,243$, respectively) [21]. In the present study, as seen in Table 1, paw thickness was found 5.41 \pm 0.40 , $6.60 \pm 0.17,6.69 \pm 0,18$ and $6.79 \pm 022$, respectively. It was found that a low dose of GLA did not prevent CAR-induced paw edema.

Table 1. According to time, change of paw thickness in the CAR-induced paw edema. Data are expressed as mean \pm S.E.M. $(n=6)$ and one-way ANOVA followed by Tukey's multiple range test. Carrageenan treated lead

to edema ( ${ }^{*} \mathrm{p}<0.001$ ) as compared to Control group, pretreatment of 20 and $40 \mathrm{mg} / \mathrm{kg}$ dose of GLA found statistically significant $\left({ }^{* *} \mathrm{p}<0.05,{ }^{* * *} \mathrm{P}<0.01\right.$, respectively) as compared to CAR group.

\begin{tabular}{|c|c|c|c|c|c|c|c|}
\hline \multirow[t]{2}{*}{$\begin{array}{l}\text { Treatment } \\
\text { groups }\end{array}$} & \multicolumn{6}{|c|}{ According to time, change of paw thickness (mm) } & \multirow[b]{2}{*}{$\begin{array}{l}\text { \% change of } \\
\text { edema at } 4 \mathrm{~h}\end{array}$} \\
\hline & Before inj. & $\mathbf{O} \mathbf{h}$ & $1 \mathrm{~h}$ & $2 \mathrm{~h}$ & $3 \mathbf{h}$ & $4 \mathrm{~h}$ & \\
\hline Salin control & $4.63 \pm 0.22$ & $4.73 \pm 0.22$ & $4.76 \pm 0.24$ & $4.83 \pm 0.03$ & $4.81 \pm 0.04$ & $4.83 \pm 0.03$ & $2.85 \%$ \\
\hline CAR+Vehicle & $4.35 \pm 0.34$ & $4.53 \pm 0.33$ & $5.67 \pm 0.47$ & $6.56 \pm 0.05$ & $6.55 \pm 0.12$ & $6.84 \pm 0.23$ & $49.17 \%$ \\
\hline CAR & $4.15 \pm 0.26$ & $4.33 \pm 0.27$ & $5.41 \pm 0.40^{*}$ & $6.60 \pm 0.17 *$ & $6.69 \pm 0.18^{*}$ & $6.79 \pm 0.22 *$ & $50.17 \%$ \\
\hline GLA+10 & $4.23 \pm 0.31$ & $4.37 \pm 0.34$ & $5.35 \pm 0.37$ & $6.38 \pm 0.08$ & $6.41 \pm 0.19$ & $6.56 \pm 0.17$ & $44,00 \%$ \\
\hline GLA+20 & $4.28 \pm 0.34$ & $4.28 \pm 0.34$ & $5.05 \pm 0.39$ & $5.80 \pm 0.12 * *$ & $5.73 \pm 0.28 * *$ & $5.86 \pm 0.25 * *$ & $27,00 \%$ \\
\hline GLA+40 & $4.53 \pm 0.33$ & $4.63 \pm 0.33$ & $5.04 \pm 0.44 * * *$ & $5.33 \pm 0.11 * * *$ & $5.38 \pm 0.22 * * *$ & $5.47 \pm 0.17 * * *$ & $17,00 \%$ \\
\hline
\end{tabular}

However, higher doses of GLA, especially $40 \mathrm{mg} / \mathrm{kg}$ dose, clearly decreased CARinduced paw edema and inflammation. Accumulating evidence has indicated that GLA attenuates acute lung injury via calcium-sensitive potassium $\left(\mathrm{BK}_{\mathrm{Ca}}\right)$ channels [22-24], in our 
study, the anti-edematous effect of GLA maybe via these channels. In a study by El-Ashmawy et al., GLA has shown that the effect of anti-inflammatory of GLA is via downregulation of iNOS in rats with ulcerative colitis [11]. Moreover, they demonstrated that an imbalance between the generation of ROS and an impaired antioxidant defense system results in oxidative stress. So, it maybe indicated that GLA can reduce oxidative stress by improving the impaired antioxidant defense system. Consistent with previous findings, the anti-ulcer effect of licorice root has been shown to be the result of blocking of the histamine receptor [25]. Due to endogen histamine, which secretions from mast cells that increase microvascular permeability [26,27], the anti-exudate effect of GLA may decrease histamine secretion.

In terms of microvascular leakage change of edematous paw, as seen Figure 2, GLA prevented the microvascular escape from blood vessel to inflammatory region. Our previous study proved that GLA inhibits inflammation by activating BKCa channels, causing cells to hyperpolarize [14]. Moreover, in another study, GLA was shown to attenuate functional failure in rat ileum smooth muscle induced by ischemia/reperfusion by upregulating cAMP [28]. The pretreatment with GLA reversed the effects of CAR, which suggests a significant interaction between CAR and microvascular leakage. Thus, GLA mediates the anti-edematous and antiplasma extravasations effects of CAR. The present study increases the understanding that the pharmacological level of GLA plays on anti-inflammatory effects by demonstrating that GLA decreases CAR-induced paw edema. These effects were similar in magnitude to those produced by the GLA, as well as the nonselective COX inhibitor diclofenac [29]. The anti-plasma escape effects of GLA may be mediated by the blockage of the histamine receptor. These results suggest that the GLA reduces inflammation through the suppression of neurogenic inflammation when administered after CAR.

The other criteria for determining the extent of paw edema are to measure paw thickness. In the previous study, the administration of CAR caused significant edema in paw tissue [21]. Consistent with previous findings, results of the present investigation also showed that, in the carrageenan-induced paw of rats, total protein content in paw tissue increased compared to the saline control group, whereas GLA administration reduced total protein content in paw tissue [30].

Eventually, combining the above studies, we discovered that GLA had more significant therapeutic effects of demonstrates on plasma leakage and acute inflammation. The results indicated that GLA, glycyrrhizic acid and glycyrrhetinic acid were the main medicinal ingredients in Glycyrrhiza glabra. Our experimental studies provide evidence that supports the hypothesis that the activation of GLA may have beneficial effects against inflammatory processes.

\section{Conclusions}

The results of our study suggest that pretreat-GLA to CAR-induced paw edema of rats via anti-inflammatory potential through inhibition of parameters such as microvascular escape and anti-edematous effect. These findings may be a new treatment of inflammation by antiprotein leakage of GLA.

\section{Funding}

None. 


\section{Acknowledgments}

This study was presented orally at the International Congress of Academic Research. The authors would like to thank those people who helped in this study.

\section{Conflict of Interest}

The authors declare that there are no conflicts of interest.

\section{References}

1. Parlar, A.; Arslan, S.O.; Doğan, M.F.; Çam, S.A.; Yalçin, A.; Elibol, E.; Özer, M.K.; Üçkardeş, F.; Kara, H. The exogenous administration of CB2 specific agonist, GW405833, inhibits inflammation by reducing cytokine production and oxidative stress. Exp. Ther. Med. 2018, 16, 4900-4908, https://doi.org/10.3892/etm.2018.6753.

2. Experimental evidences of antidiabetic activity of aqueous extract of Cressa cretica L. on streptozotocin induced diabetes in rats. Lett. Appl. NanoBioScience 2020, 9, 774-778, https://doi.org/10.33263/lianbs91.774778.

3. Parlar, A.; Arslan, S.O. Thymoquinone reduces ischemia and reperfusion-induced intestinal injury in rats, through anti-oxidative and anti-inflammatory effects. Turkish J. Surg. 2020, 36, 96-104, https://doi.org/10.5578/TURKJSURG.4583.

4. Dumlu, F.A.; Aydin, T.; Odabasoglu, F.; Berktas, O.A.; Kutlu, Z.; Erol, H.S.; Halici, M.B.; Cadirci, E.; Cakir, A. Anti-inflammatory and antioxidant properties of jervine, a sterodial alkaloid from rhizomes of Veratrum album. Phytomedicine 2019, 55, 191-199, https://doi.org/10.1016/J.PHYMED.2018.06.035.

5. Hassan, F.I.; Zezi, A.U.; Yaro, A.H.; Danmalam, U.H. Analgesic, anti-inflammatory and antipyretic activities of the methanol leaf extract of Dalbergia saxatilis Hook.F in rats and mice. J. Ethnopharmacol. 2015, 166, 74-78, https://doi.org/10.1016/j.jep.2015.03.007.

6. Güven, C.; Parlar, A. Glabridin Relaxes Vascular Smooth Muscles by Activating BKCa Channels and Inhibiting Phosphodiesterase in Human Saphenous Vein. Curr. Med. Sci. 2021, 41, 381-389, https://doi.org/10.1007/s11596-021-2358-6.

7. Kumari, R.; Mishra, R.C.; Parkash Yadav, J. Antioxidant and cytotoxic studies of Acacia nilotica twig extract and their green synthesized silver nanoparticles. Lett. Appl. NanoBioScience Appl. 2020, 9, 975-980, https://doi.org/10.33263/LIANBS92.975980.

8. Zhang, L.-P.; Zhao, Y.; Liu, G.-J.; Yang, D.-G.; Dong, Y.-H.; Zhou, L.-H. Glabridin attenuates lipopolysaccharide-induced acute lung injury by inhibiting p38MAPK/ERK signaling pathway. Oncotarget 2017, 8, 18935-18942, https://doi.org/10.18632/oncotarget.14277.

9. Li, P.; Li, Y.; Jiang, H.; Xu, Y.; Liu, X.; Che, B.; Tang, J.; Liu, G.; Tang, Y.; Zhou, W.; Zhang, L.; Dong, C.; Chen, H.; Zhang, K.; Du, Z. Glabridin, an isoflavan from licorice root, ameliorates imiquimod-induced psoriasis-like inflammation of BALB/c mice. Int. Immunopharmacol. 2018, 59, 243-251, https://doi.org/10.1016/j.intimp.2018.04.018.

10. Sidhu, P.; Shankargouda, S.; Rath, A.; Hesarghatta Ramamurthy, P.; Fernandes, B.; Kumar Singh, A. Therapeutic benefits of liquorice in dentistry. J. Ayurveda Integr. Med. 2018, https://doi.org/10.1016/j.jaim.2017.12.004.

11. El-Ashmawy, N.E.; Khedr, N.F.; El-Bahrawy, H.A.; El-Adawy, S.A. Downregulation of iNOS and elevation of cAMP mediate the anti-inflammatory effect of glabridin in rats with ulcerative colitis. Inflammopharmacology 2018, 26, 551-559, https://doi.org/10.1007/s10787-017-0373-9.

12. Link, P.; Wink, M. Isoliquiritigenin exerts antioxidant activity in Caenorhabditis elegans via insulin-like signaling pathway and SKN-1. Phytomedicine 2019, 55, 119-124, https://doi.org/10.1016/j.phymed.2018.07.004.

13. Parlar, A.; Arslan, S.O.; Çam, S.A. Glabridin alleviates inflammation and nociception in rodents by activating BKCa channels and reducing NO levels. Biol. Pharm. Bull. 2020, 43, 884-897, https://doi.org/10.1248/bpb.b20-00038.

14. Parlar, A.; Annaç, E.; Arslan, S.O.; Çam, S.A. Pretreatment With Glabridin Prevents Carrageenan-Induced Inflammation: The Roles For Cytokines And Oxidative Stress Production. Farmacia 2021, 69, 1, https://doi.org/10.31925/farmacia.2021.1.18. 
15. Hanci, M.; Parlar, A.; Arslan, S.O. Siçan İnce Barsak İskemi/Reperfüzyon Hasarinda İleum Ve Akciğer Dokusunda Görülen Damar Dişina Protein Kaçişinin, Kanabinoid 2 Reseptör Agonisti (Am-1241) İle Kontrolü. Konuralp Tıp Derg. 2020, 12, 73-79, https://doi.org/10.18521/ktd.498768.

16. Parlar, A.; Arslan, S.O. Anti-Inflammatory Effects Of Cannabinoid 2 Receptor Agonist, Gw405833, In A Model Of Carrageenan-Induced Acute Inflammation Of The Rat Paw. Int. J. Sci. Res. 2019, 8, 55-58.

17. Bhukya, B.; Anreddy, R.N.R.; William, C.M.; Gottumukkala, K.M. Analgesic and anti-inflammatory activities of leaf extract of Kydia calycina Roxb. Bangladesh J. Pharmacol. 2009, 4, 101-104, https://doi.org/10.3329/bjp.v4i2.2112.

18. Anwar, D.A.; Eid, H.R.; El-Chaghaby, G.A. Nutritional and Antioxidant Properties of Mango Juice and Aloe Vera Gel and their Effect on Diabetic Rats. Lett. Appl. NanoBioScience Appl. 2020, 9, 1602-1614, https://doi.org/10.33263/LIANBS94.16021614.

19. Jancso, L.N.; Jancs6-Gabor, A.; Szolcsanyi, J. The Role Of Sensory Nerve Endings In Neurogenic Inflammation Induced In Human Skin And In The Eye And Paw Of The Rat; 1968; Vol. 32.

20. Bubulica, M.-V.; Chirigiu, L.; Grumezescu, A.M.; Popescu, A.; Simionescu, A. Screening of antioxidant potential of Lonicera tatarica, Viburnum opulus and Sambucus ebulus L. by multiple in vitro assays. J. Med. Plants Res. 2012, 6, 544-552, https://doi.org/10.5897/jmpr11.1570.

21. Solanki, H.K.; Shah, D.A.; Maheriya, P.M.; Patel, C.A. Evaluation of anti-inflammatory activity of probiotic on carrageenan-induced paw edema in Wistar rats. Int. J. Biol. Macromol. 2015, 72, 1277-1282, https://doi.org/10.1016/J.IJBIOMAC.2014.09.059.

22. Chanda, D.; Prieto-Lloret, J.; Singh, A.; Iqbal, H.; Yadav, P.; Snetkov, V.; Aaronson, P.I. Glabridin-induced vasorelaxation: evidence for a role of BKCa channels and cyclic GMP. Life Sci. 2016, 165, 26-34, https://doi.org/10.1016/j.lfs.2016.09.018.

23. Dogan, M.F.; Parlar, A.; Cam, S.A.; Tosun, E.M.; Uysal, F.; Arslan, S.O. Glabridin attenuates airway inflammation and hyperresponsiveness in a mice model of ovalbumin-induced asthma. Pulm. Pharmacol. Ther. 2020, 101936, https://doi.org/10.1016/j.pupt.2020.101936.

24. Parlar, A.; Arslan, S.O.; Yumrutas, O.; Elibol, E.; Yalcin, A.; Uckardes, F.; Aydin, H.; Dogan, M.F.; Kayhan Kustepe, E.; Ozer, M.K. Effects of cannabinoid receptor 2 synthetic agonist, AM1241, on bleomycin induced pulmonary fibrosis. Biotech. Histochem. 2020, 1-12, https://doi.org/10.1080/10520295.2020.1758343.

25. Kim, D.-C.; Choi, S.-Y.; Kim, S.-H.; Yun, B.-S.; Yoo, I.-D.; Reddy, N.R.P.; Yoon, H.S.; Kim, K.-T. Isoliquiritigenin Selectively Inhibits H2 Histamine Receptor Signaling. Mol. Pharmacol. 2006, 70, 493-500, https://doi.org/10.1124/mol.106.023226.

26. Oktay ARSLAN, S. Morphine modulates microvascular leakage dose-dependently in the airway of ovalbumin-sensitized rats. Turk J Med Sci 2010, 40, 279-286, https://doi.org/10.3906/sag-0812-11.

27. Büyükokuroğlu, M.E. Anti-inflammatory and anti-nociceptive properties of dantrolene sodium in rats and mice. Pharmacol. Res. 2002, 45, 455-460, https://doi.org/10.1006/phrs.2002.0970.

28. Parlar, A.; Çam, S.A.; Arslan, S.O. Glabridin alleviates ischemia/reperfusion-induced functional failure of smooth muscle of rat ileum by upregulating the camp. Bol. Latinoam. y del Caribe Plantas Med. y Aromat. 2020, 19, https://doi.org/10.37360/blacpma.20.19.5.39.

29. Sakat, S.S.; Mani, K.; Demidchenko, Y.O.; Gorbunov, E.A.; Tarasov, S.A.; Mathur, A.; Epstein, O.I. Retraction Note: Release-active dilutions of diclofenac enhance anti-inflammatory effect of diclofenac in carrageenan-induced rat paw edema model. Inflammation 2021, 44, 810, https://doi.org/10.1007/s10753-0139705-0.

30. Qamar, W.; Khan, R.; Khan, A.Q.; Rehman, M.U.; Lateef, A.; Tahir, M.; Ali, F.; Sultana, S. Alleviation of lung injury by glycyrrhizic acid in benzo(a)pyrene exposed rats: Probable role of soluble epoxide hydrolase and thioredoxin reductase. Toxicology 2012, 291, 25-31, https://doi.org/10.1016/j.tox.2011.10.012. 